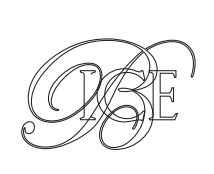

\title{
LA BALANZA COMERCIAL AGROALIMENTARIA EN 2020
}

En este artículo se analiza la evolución de los principales sectores y mercados agrarios durante el año 2020, así como los factores más importantes que determinan el comportamiento de nuestra balanza agroalimentaria ${ }^{1}$.

Se ha incluido el análisis sectorial de los productos de los veinticuatro primeros capítulos del arancel.

Palabras clave: importaciones, exportaciones, comercio exterior, agricultura, España, 2020.

Clasificación JEL: Q10, Q17.

\section{Evolución general}

De acuerdo con los datos de comercio exterior (Cuadro 1), la balanza comercial agroalimentaria, que comprende los veinticuatro primeros capítulos del arancel, ha registrado en 2020 un superávit de cerca de 18.000 millones de euros y una ratio de cobertura de $150,9 \%$. El superávit ha sido mayor al de 2019 y es el máximo valor registrado desde el año 2003, que en los últimos veinte años ha contado con un saldo positivo en la balanza comercial. Desde entonces, incluida la crisis económica, así como los importantes acontecimientos que han

\footnotetext{
* Ministerio de Industria, Comercio y Turismo.

Versión de septiembre de 2021.

DOI: https://doi.org/10.32796/bice.2021.3139.7284

Por limitaciones de espacio no se ha podido incluir el análisis sectorial de todos los productos de los veinticuatro primeros capítulos del arancel, sino únicamente los cuadros relativos a su comercio exterior. La versión completa de la balanza agroalimentaria correspondiente a 2020 se encuentra en https://comercio.gob.es/ImportacionExportacion/Informes Estadisticas/Paginas/Historico-Balanza.aspx
}

tenido lugar en 2020 (Brexit, pandemia, aplicación de medidas arancelarias por EE. UU.), España ha mantenido la voluntad exportadora de nuestro sector agroalimentario, incluso la ha aumentado. En el Gráfico 1 también se puede observar esta evolución positiva, con un aumento de la divergencia entre las exportaciones y las importaciones a partir de 2007, que da lugar a un aumento progresivo del saldo, y muy intenso en 2020.

En 2020, las exportaciones agroalimentarias (Cuadro 2) supusieron 53.255 millones de euros y 37.569 .443 toneladas. En relación con la exportación total de bienes (261.175 millones de euros), las exportaciones agroalimentarias significaron el $20,4 \%$, por encima de la participación del año 2019 (17,6\%).

Con respecto al año 2019, se ha producido un aumento en valor de un 3,9\% (1.988 millones de euros) y en volumen del 0,1\% (25.835 toneladas). 
CUADRO 1

EVOLUCIÓN DEL COMERCIO EXTERIOR ESPAÑOL DE PRODUCTOS AGROALIMENTARIOS

(Miles de euros)

\begin{tabular}{|c|c|c|c|c|c|c|}
\hline \multirow{2}{*}{ Año } & \multirow{2}{*}{ Exportación } & \multirow{2}{*}{ Importación } & \multirow{2}{*}{ Saldo } & \multirow{2}{*}{ Cobertura (\%) } & \multicolumn{2}{|c|}{ \% sobre total mercancías } \\
\hline & & & & & Exportación & Importación \\
\hline 2006 & 23.883.309 & 22.697 .096 & 1.186 .213 & 105,2 & 14,0 & 8,6 \\
\hline 2007 & 25.861 .548 & 25.530 .201 & 331.346 & 101,3 & 14,0 & 9,0 \\
\hline 2008 & 27.811 .138 & 26.912.110 & 899.028 & 103,3 & 14,7 & 9,5 \\
\hline 2009 & 26.520 .841 & 23.888.612 & 2.632 .230 & 111,0 & 16,6 & 11,6 \\
\hline 2010 & 29.100 .551 & 25.753 .433 & 3.347 .118 & 113,0 & 15,6 & 10,7 \\
\hline 2011 & 32.168 .087 & 28.357 .730 & 3.810 .356 & 113,4 & 14,9 & 10,8 \\
\hline 2012 & 35.628 .140 & 29.225 .268 & 6.402 .872 & 121,9 & 15,8 & 11,3 \\
\hline 2013 & 37.195 .596 & 28.814 .872 & 8.380 .724 & 129,1 & 15,8 & 11,4 \\
\hline 2014 & 38.687 .873 & 29.636 .446 & 9.051 .427 & 130,5 & 16,1 & 11,2 \\
\hline 2015 & 42.057 .749 & 32.293 .044 & 9.764 .705 & 130,2 & 16,8 & 11,8 \\
\hline 2016 & 44.613 .193 & 33.422 .076 & 11.191.117 & 133,5 & 17,4 & 12,2 \\
\hline 2017 & 47.528 .535 & 36.003 .519 & 11.525 .016 & 132,0 & 17,2 & 11,9 \\
\hline 2018 & 47.910 .440 & 36.455 .841 & 11.454 .599 & 131,4 & 16,8 & 11,4 \\
\hline 2019 & 51.266 .864 & 37.161 .243 & 14.105 .621 & 138,0 & 17,6 & 11,5 \\
\hline $2020^{*}$ & 53.255 .161 & 35.297 .398 & 17.957 .763 & 150,9 & 20,4 & 12,9 \\
\hline
\end{tabular}

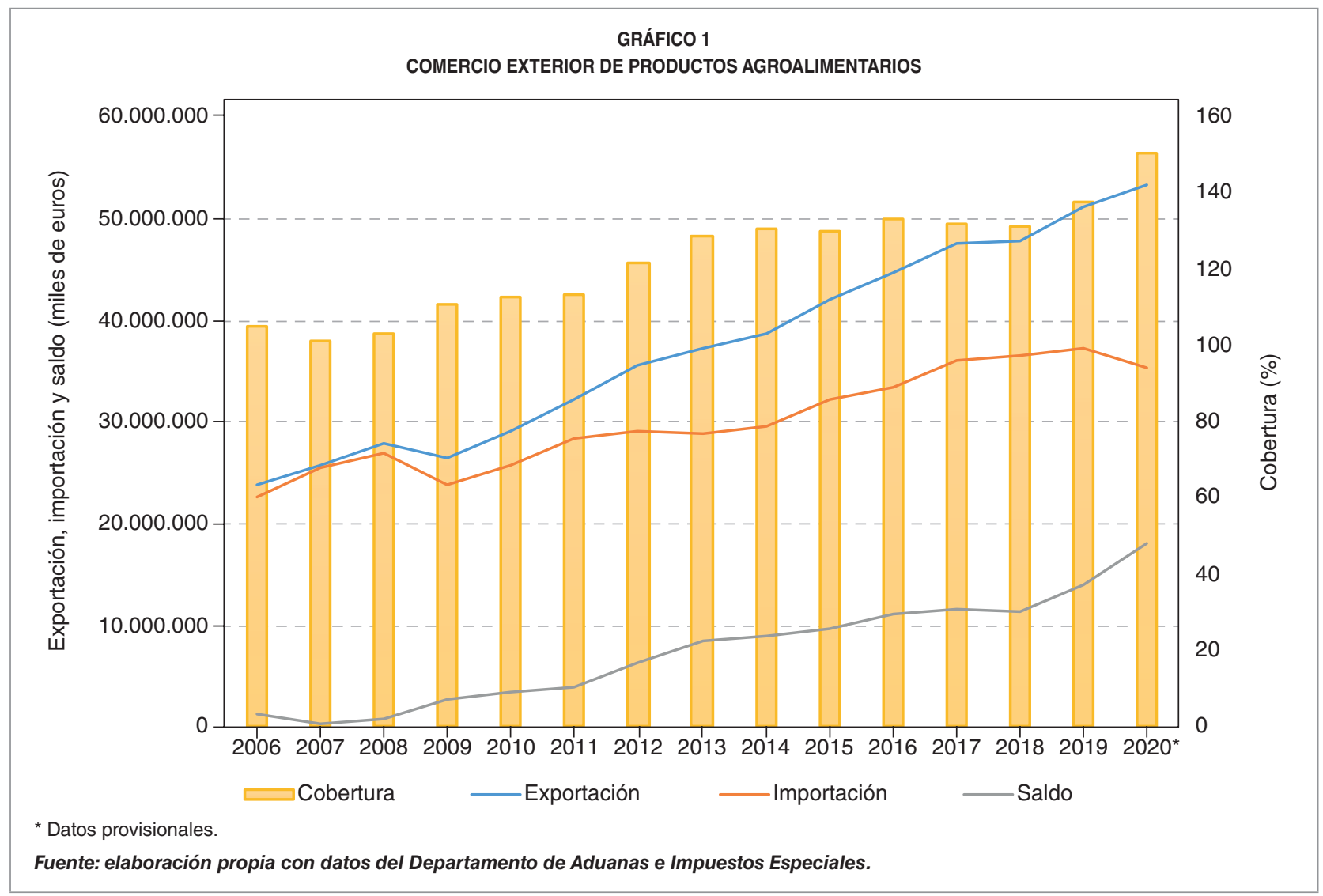


En volumen, hay nueve capítulos (igual que en los dos años anteriores) que superan el millón de toneladas de exportación y suponen el $84,3 \%$ del total exportado: 8 (frutas y frutos $\sin$ conservar), 7 (legumbres y hortalizas sin conservar), 22 (bebidas), 2 (carne y despojos comestibles), 20 (conservas y zumos vegetales), 15 (grasas y aceites animales o vegetales), 23 (residuos de la industria alimentaria), 12 (semillas oleaginosas y plantas industriales) y 10 (cereales).

En cuanto al valor, doce capítulos (también igual que en los dos años anteriores) han superado los 1.000 millones de euros, suponiendo el $89,3 \%$ del total: capítulos 8 (frutas y frutos sin conservar), 2 (carne y despojos comestibles), 7 (legumbres y hortalizas sin conservar), 22 (bebidas), 15 (grasas y aceites animales o vegetales), 20 (conservas vegetales y zumos), 3 (pescados, crustáceos, moluscos), 19 (productos a base de cereales), 16 (conservas de carne o de pescado), 21 (preparaciones alimenticias diversas), 4 (leche y productos lácteos y huevos) y 23 (residuos de la industria alimentaria).

En un año difícil para el comercio exterior, la subida del volumen de las exportaciones se ha debido principalmente al capítulo 2 (carne y despojos comestibles), con un aumento de 548.771 toneladas. También ha aumentado la exportación de otros productos, por debajo de 100.000 toneladas. Proporcionalmente, destacan en volumen los incrementos de los capítulos 9 (café, té, yerba mate y especias), 2 (carne y despojos comestibles), 13 (jugos y extractos vegetales) y 16 (conservas de carne o de pescado), cada uno con un aumento superior al $10 \%$. Por otro lado, han disminuido las exportaciones en más de un $10 \%$, además del avituallamiento, el capítulo 14 (materias trenzables), 17 (azúcares y productos de confitería sin cacao), 24 (tabaco y sus sucedáneos) y 1 (animales vivos); y, en menos del 10\%, los capítulos 3 (pescados, crustáceos, moluscos), 8 (frutas y frutos sin conservar), 18 (cacao y sus preparaciones), 10 (cereales), 22 (bebidas) y 7 (legumbres y hortalizas sin conservar). El tonelaje de los demás capítulos 1 a 24 del arancel ha aumentado, salvo los capítulos 6 (plantas y flores) y 15 (grasas y aceites animales o vegetales), que prácticamente no han variado con respecto a 2019.

Respecto del valor, destaca el incremento de las exportaciones en los capítulos 2 (carne y despojos comestibles), 8 (frutas y frutos $\sin$ conservar), 7 (legumbres y hortalizas sin conservar), 16 (conservas de carne o de pescado), 23 (residuos de la industria alimentaria) y 21 (preparaciones alimenticias diversas), los cinco con aumentos superiores a 100 millones de euros. El aumento de la carne ha sido muy elevado por segundo año consecutivo, de 1.275 millones de euros. También se observa aumento de la exportación en los capítulos 19 (productos a base de cereales), 4 (leche, productos lácteos y huevos), 9 (café, té, yerba mate y especias), 20 (conservas y zumos vegetales), 13 (jugos y extractos vegetales), 12 (semillas oleaginosas y plantas industriales), 10 (cereales), 11 (productos de la molinería y malta) y 5 (otros productos de origen animal). Proporcionalmente, los productos con mayor aumento (superior al 10\%) en las exportaciones han sido los de los capítulos 2 (carne y despojos comestibles), 23 (residuos de la industria alimentaria), 9 (café, té, yerba mate y especias) y 16 (conservas de carne o de pescado).

Las importaciones agroalimentarias (Cuadro 3) supusieron 35.297 millones de euros y 40.715 .703 toneladas. En relación con la importación total española de $\square$ 
bienes (274.598 millones de euros), el sector agroalimentario ha supuesto el $12,9 \%$ del valor total importado, superior al porcentaje de 2019 (11,5\%).

Con respecto al año anterior, y en términos de valor, en 2020 se ha producido un descenso del $5 \%$ de las importaciones agroalimentarias (-1.864 millones de euros), debido fundamentalmente a los capítulos 3 (pescados, crustáceos y moluscos), 10 (cereales), 22 (bebidas), 2 (carne y despojos comestibles), 24 (tabaco y sus sucedáneos), 16 (conservas de carne o de pescado), 4 (leche, productos lácteos y huevos) y 19 (productos derivados de cereales), cada uno con una reducción superior a 100 millones de euros. En términos porcentuales, las mayores disminuciones se han producido en los capítulos 2 (carne y despojos comestibles), 22 (bebidas), 10 (cereales), 3 (pescados, crustáceos y moluscos), 5 (otros productos de origen animal), 14 (materias trenzables), 24 (tabaco y sus sucedáneos) y 6 (plantas y flores), cada uno con una caída superior al $10 \%$. Ha habido un aumento de más de 100 millones de euros en las importaciones de los capítulos 15 (grasas y aceites animales o vegetales) y 8 (frutas y frutos sin conservar). Otros productos con incremento de las importaciones con respecto a 2019 han sido los de los capítulos 9 (café, té, yerba mate y especias), 23 (residuos de la industria alimentaria), 11 (productos de la molinería y malta), 1 (animales vivos), $13 \square$

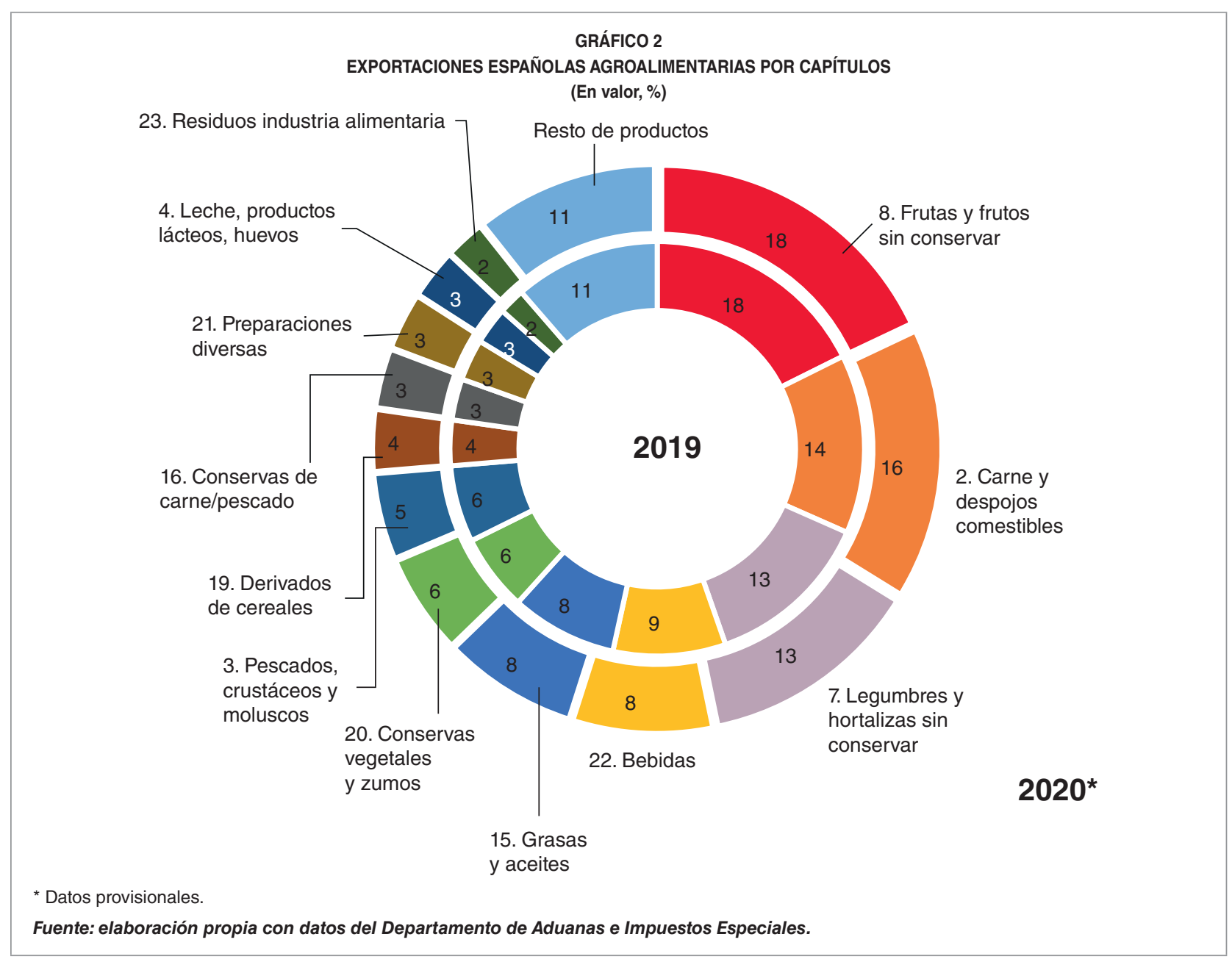


(jugos y extractos vegetales) y 12 (semillas oleaginosas y plantas industriales).

En cuanto al volumen, se ha producido una caída del 10,4\%. Con una reducción superior a 100.000 toneladas se encuentran los capítulos 10 (cereales), 23 (residuos de la industria alimentaria), 17 (azúcares y productos de confitería sin cacao) y 12 (semillas oleaginosas y plantas industriales). Destacan los cereales, con una diferencia con respecto a 2019 de -3.668.253 toneladas. En términos porcentuales, las mayores disminuciones han tenido lugar en los capítulos 17 (azúcares y productos de confitería sin cacao), 10 (cereales), 21 (preparaciones alimenticias diversas), 23 (residuos de la industria alimentaria), 14 (materias trenzables) y 13 (jugos y extractos vegetales), con variaciones superiores al $10 \%$. Con una subida superior a 100.000 toneladas se encuentran el capítulo 15 (grasas y aceites animales 0 vegetales) y el 11 (productos de la molinería y malta). Otros capítulos con aumento de las importaciones en volumen en 2020 son el 8 (frutas y frutos sin conservar), el 1 (animales vivos), el 9 (café, té, yerba mate y especias), el 7 (legumbres y hortalizas sin conservar) y el 6 (plantas y flores).

El esquema de nuestras importaciones es similar al de años anteriores. En volumen hay nueve capítulos que superan el millón de toneladas. Estos son, por orden de importancia: capítulos 10 (cereales), 23 (residuos de la industria alimentaria), 12 (semillas oleaginosas y plantas industriales), 15 (grasas y aceites animales o vegetales), 7 (legumbres y hortalizas sin conservar), 8 (frutas y frutos sin conservar), 17 (azúcares, artículos confitería), 3 (pescados, crustáceos y moluscos) y 22 (bebidas). Todos ellos suponen el $86,9 \%$ del total de las importaciones. Como se ha indicado, el principal capítulo es $\triangleright$

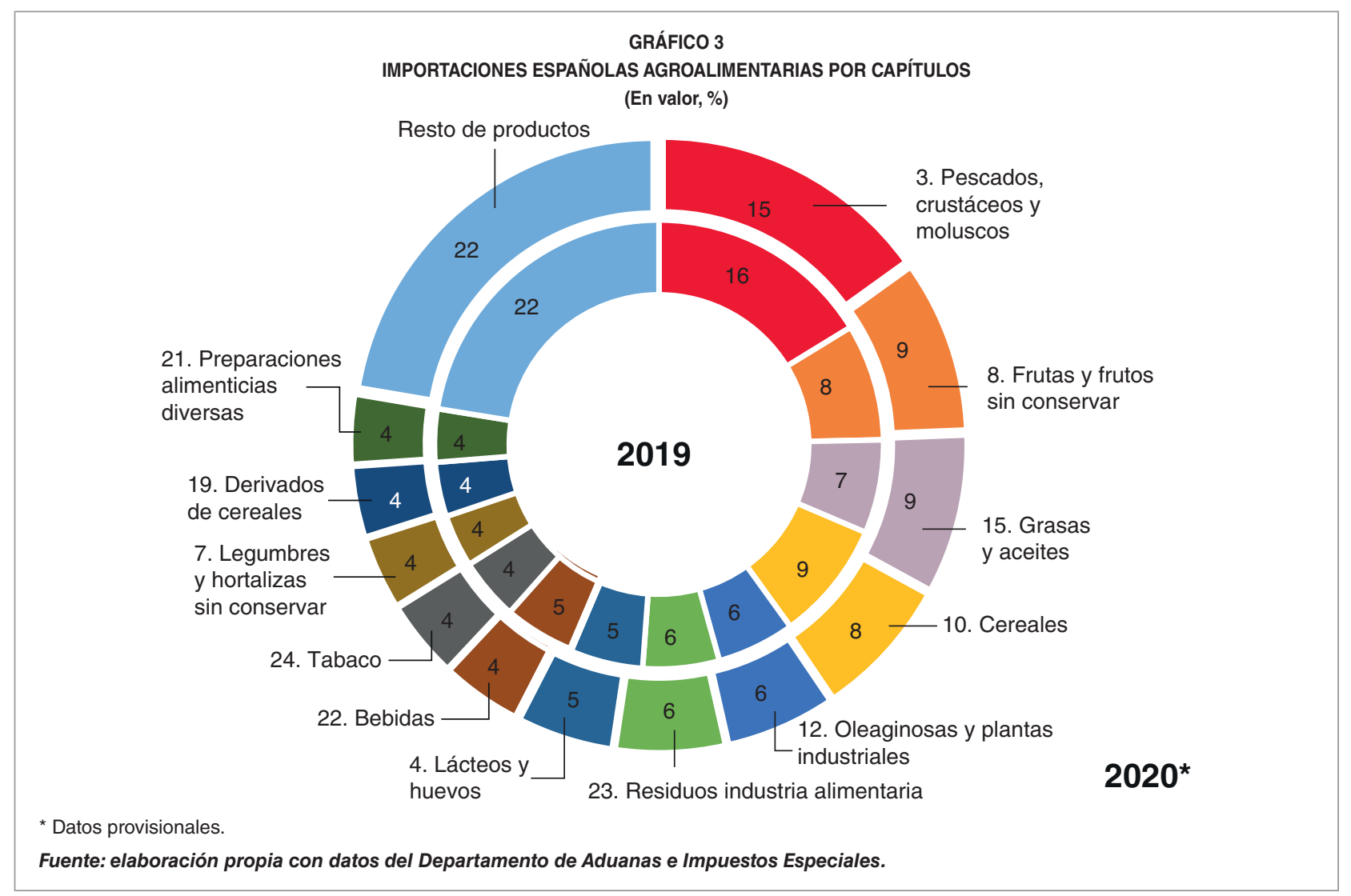




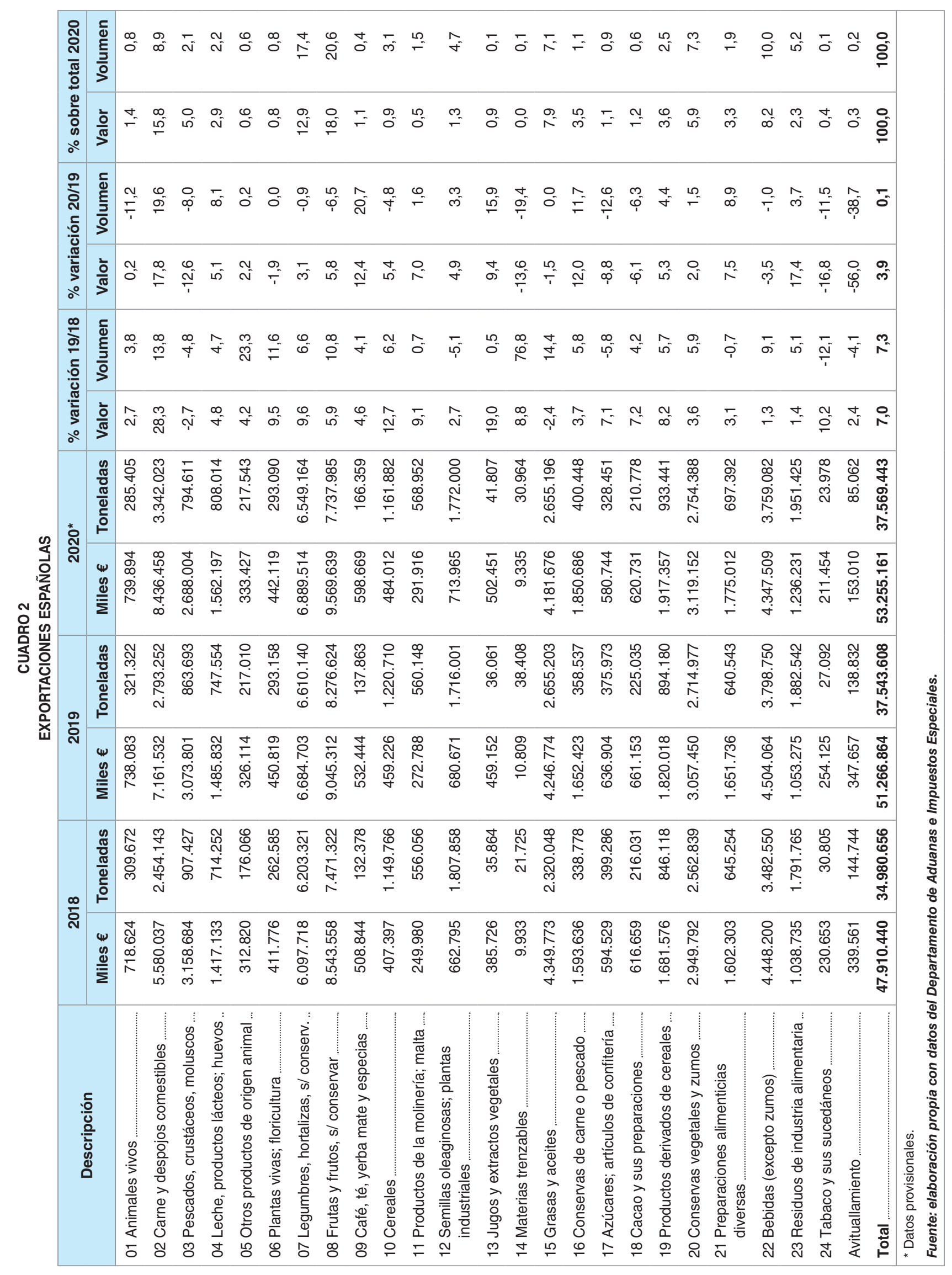




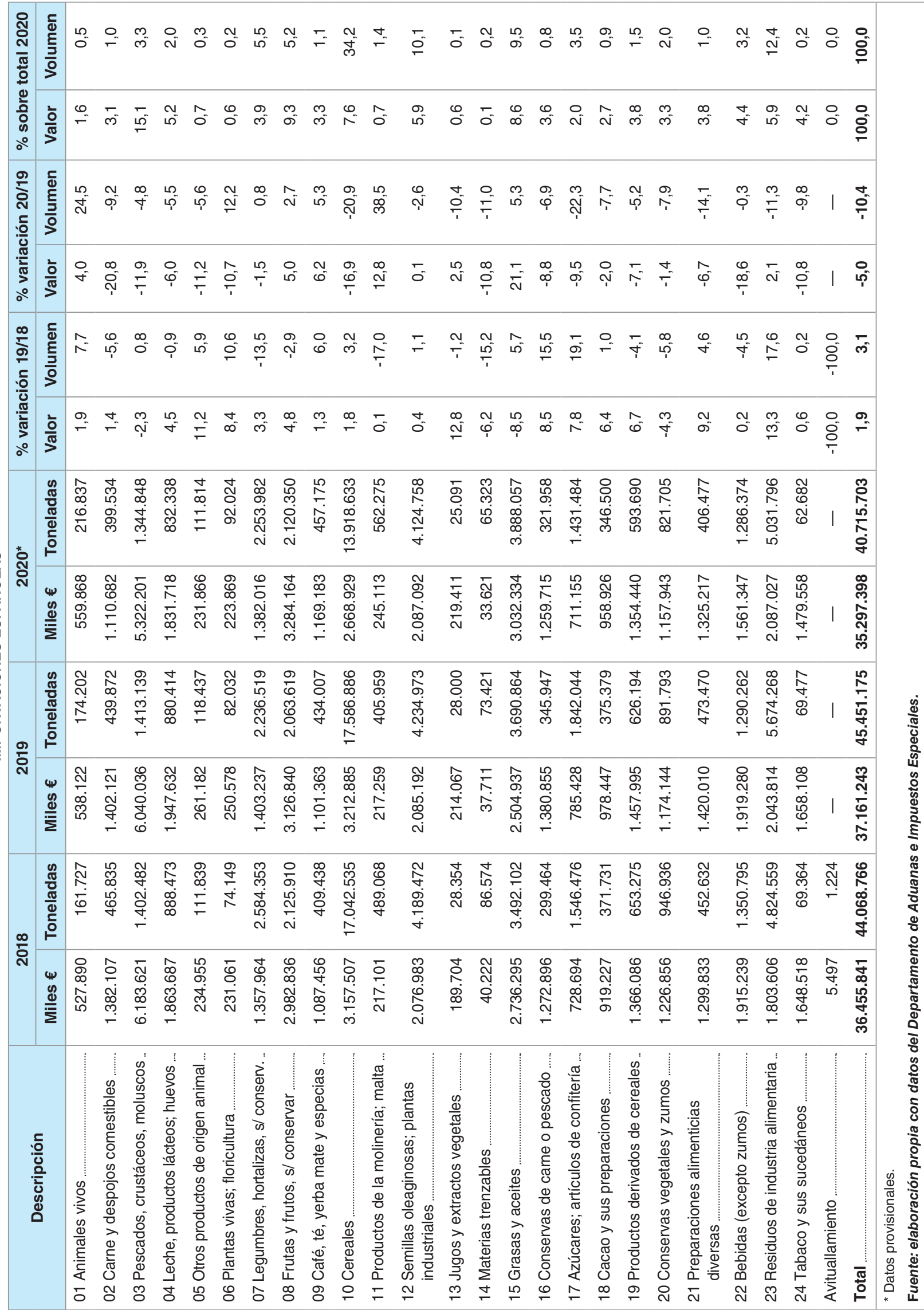


el de cereales, del que se han importado 13,9 millones de toneladas (34,2\% del total).

En cuanto al valor, hay dieciséis capítulos que han superado los 1.000 millones de euros, igual que en 2019. El más relevante es el capítulo 3 (pescados, crustáceos y moluscos), del que se han importado 5.322 millones de euros y representa el $15,1 \%$ del valor total.

Por orden de importancia se trata de los capítulos 3 (pescados, crustáceos y moluscos), 8 (frutas $y$ frutos sin conservar), 15 (grasas $y$ aceites animales o vegetales), 10 (cereales), 12 (semillas oleaginosas y plantas industriales), 23 (residuos de la industria alimentaria), 4 (leche, productos lácteos y huevos), 22 (bebidas), 24 (tabaco y sus sucedáneos), 7 (hortalizas y legumbres), 19 (productos derivados de cereales), 21 (preparaciones alimenticias diversas), 16 (conservas de carne o de pescado), 9 (café, té, yerba mate y especias), 20 (conservas y zumos vegetales) y 2 (carne y despojos comestibles). Todos ellos suponen el $91 \%$ del total.

\section{Distribución geográfica del comercio exterior agroalimentario}

\subsection{Exportaciones por destino}

Los principales destinatarios de las exportaciones españolas son los demás países de la Unión Europea (UE). En el Cuadro 4 se puede observar una disminución de nuestras exportaciones a la UE en valor $(-9,4 \%)$ y en volumen $(-12,4 \%)$, si bien esto se debe a que no se ha incluido a Reino Unido en 2020, año en que este país ha dejado de pertenecer a la Unión Europea. Si se incluyen las exportaciones a Reino Unido en 2020, la variación es poco significativa (aumento del $2 \%$ en valor y reducción del $2,1 \%$ en volumen). Las exportaciones $\square$

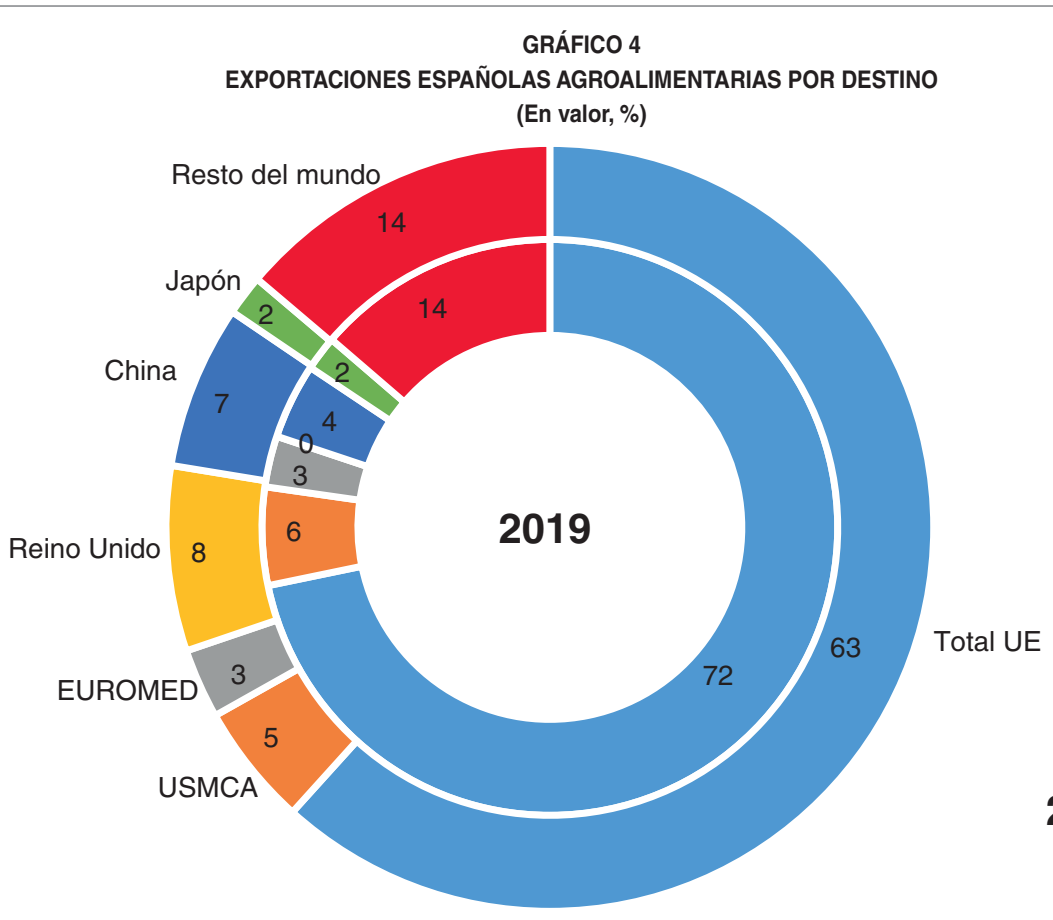

2020*

* Datos provisionales.

Fuente: elaboración propia con datos del Departamento de Aduanas e Impuestos Especiales. 


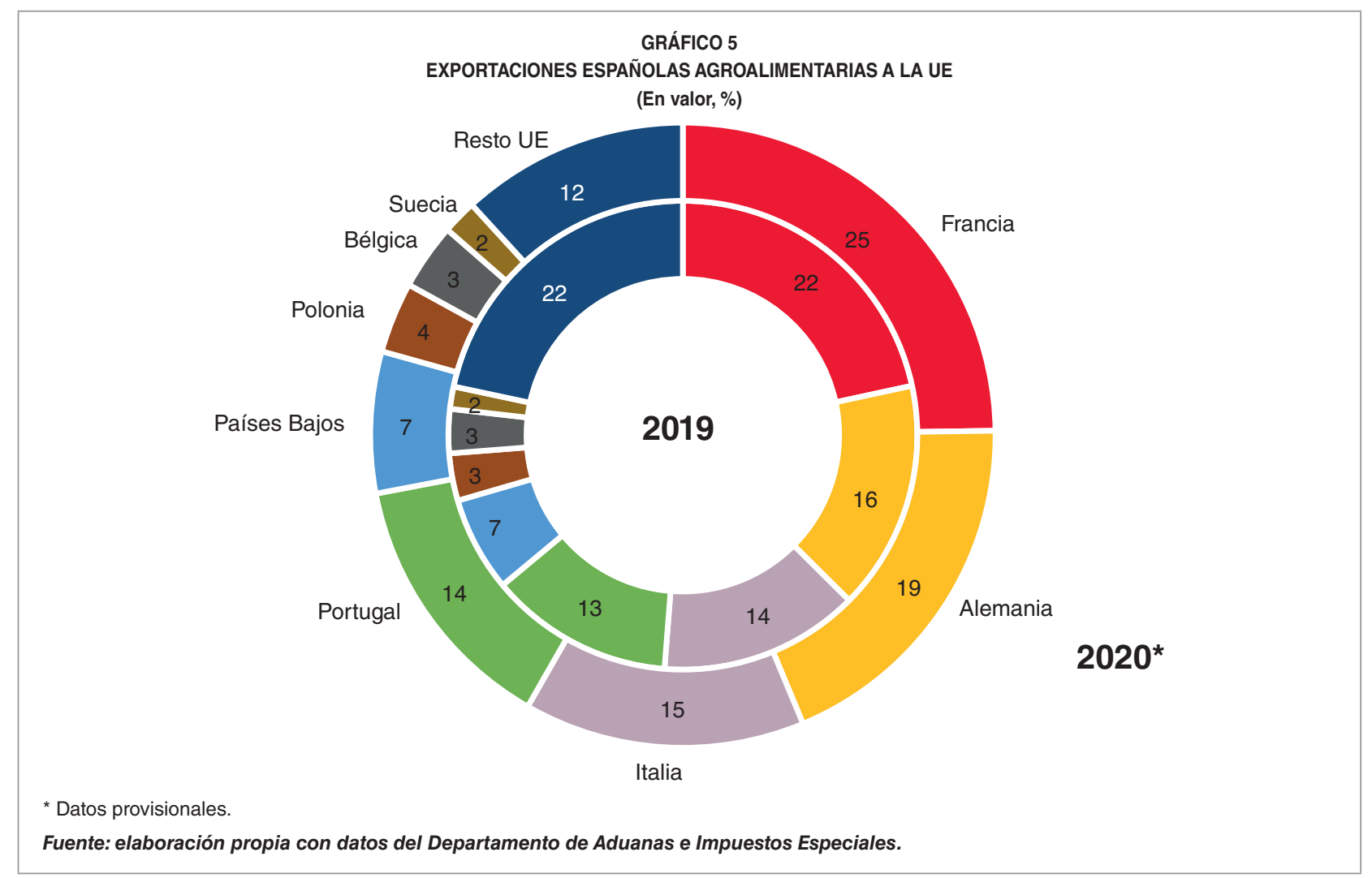

españolas a la UE representan el $66,8 \%$ de las exportaciones totales en volumen $(76,3 \%$ en 2019 ) y del $62,6 \%$ en valor $(71,7 \%$ en 2019$)$, lo que da una idea de lo que supone el Brexit en nuestras exportaciones a la UE.

Considerados de manera individual, nuestros principales mercados en la UE son: Francia ( $15,5 \%$ en valor y $17,6 \%$ en volumen), Alemania ( $11,9 \%$ en valor y $12,6 \%$ en volumen), Italia ( $9,1 \%$ en valor y $7,8 \%$ en volumen) y Portugal ( $8,6 \%$ en valor y $10,8 \%$ en volumen). Estos cuatro países suponen el $48,9 \%$ de la exportación española en volumen y el $45,1 \%$ en valor.

Fuera de la Unión Europea superan la cuota del $1 \%$ del volumen: Reino Unido (8\%), China (4,8\%), Estados Unidos (2\%), Marrue$\cos (1,7 \%)$, Arabia Saudí (1,6\%) y Emiratos Árabes Unidos (1,5\%). En valor, superan el $1 \%$ del valor de las exportaciones totales:
Reino Unido (7,9\%), China (7\%), EE. UU. $(3,9 \%)$, Japón $(1,7 \%)$, Suiza $(1,3 \%)$ y Marruecos $(1,1 \%)$.

Por bloques de países, son mercados relevantes los países que forman parte del tratado entre México, Estados Unidos y Canadá (USMCA) y los países euromediterráneos. Las exportaciones españolas a USMCA suponen el 2,8\% del volumen y el 5,2\% del valor total, y han aumentado con respecto a 2019 un $0,3 \%$ en volumen y disminuido un $1,4 \%$ en valor. Tres cuartas partes del valor de estas exportaciones tienen como destino Estados Unidos.

Nuestras exportaciones a los países euromediterráneos representan el 4,3\% en volumen y el $3 \%$ en valor, y han aumentado considerablemente en 2020 , un $10,3 \%$ en volumen y un $8 \%$ en valor. 


\subsection{Importaciones por origen}

Los principales proveedores de productos agroalimentarios (Cuadro 5) son también los demás países de la UE. En términos porcentuales sobre el total de 2020 representan en volumen el $45,1 \%$ (44,3\% en 2019$)$ y en valor el $51,2 \%$ (54\% en 2019). Al comparar con las importaciones de 2019, y en términos porcentuales, se reducen un $9,1 \%$ en volumen y un $9,9 \%$ en valor. Al igual que en el caso de las exportaciones, esto se debe a que no se ha incluido a Reino Unido en 2020 por el Brexit. Si se suman las importaciones a Reino Unido en 2020 a las de la UE, la variación es más importante que para las exportaciones (reducción del $5,5 \%$ en valor y del $6,5 \%$ en volumen).

Los principales proveedores europeos en términos de volumen son: Francia (más de 7 millones de toneladas), Portugal y Alemania (ambos con más de 1,5 millones de toneladas), y Rumanía y Países Bajos (estos dos con más de un millón de toneladas). En términos de valor, los principales proveedores son Francia, Alemania, Países Bajos, Portugal, Italia y Bélgica, todos ellos con importaciones superiores a 1.000 millones de euros, y suponen el $41,1 \%$ del valor total importado por España. Fuera de la UE, igualan o superan la cuota del $1 \%$ del volumen: Brasil (14,3\%), Ucrania (9,8\%), Argentina $(4,6 \%)$, Estados Unidos $(3,8 \%)$, Indonesia $(3,7 \%)$, Marruecos $(1,9 \%)$, China (1,5\%), Reino Unido (1,3\%), Rusia (1,3\%) y Canadá (1\%).

Por lo que respecta al valor, cuatro países de la UE superan el $5 \%$, igual que el año pasado: Francia (13\%), Alemania (8,1\%), Países Bajos $(6,7 \%)$ y Portugal $(6 \%)$. Fuera de la UE superan el $1 \%$ : Brasil (5\%), Marruecos (4,4\%), Estados Unidos (4,1\%), China (3,1\%), Argentina $(2,8 \%)$, Ucrania $(2,7 \%)$, Indonesia $(2,7 \%), \triangleright$

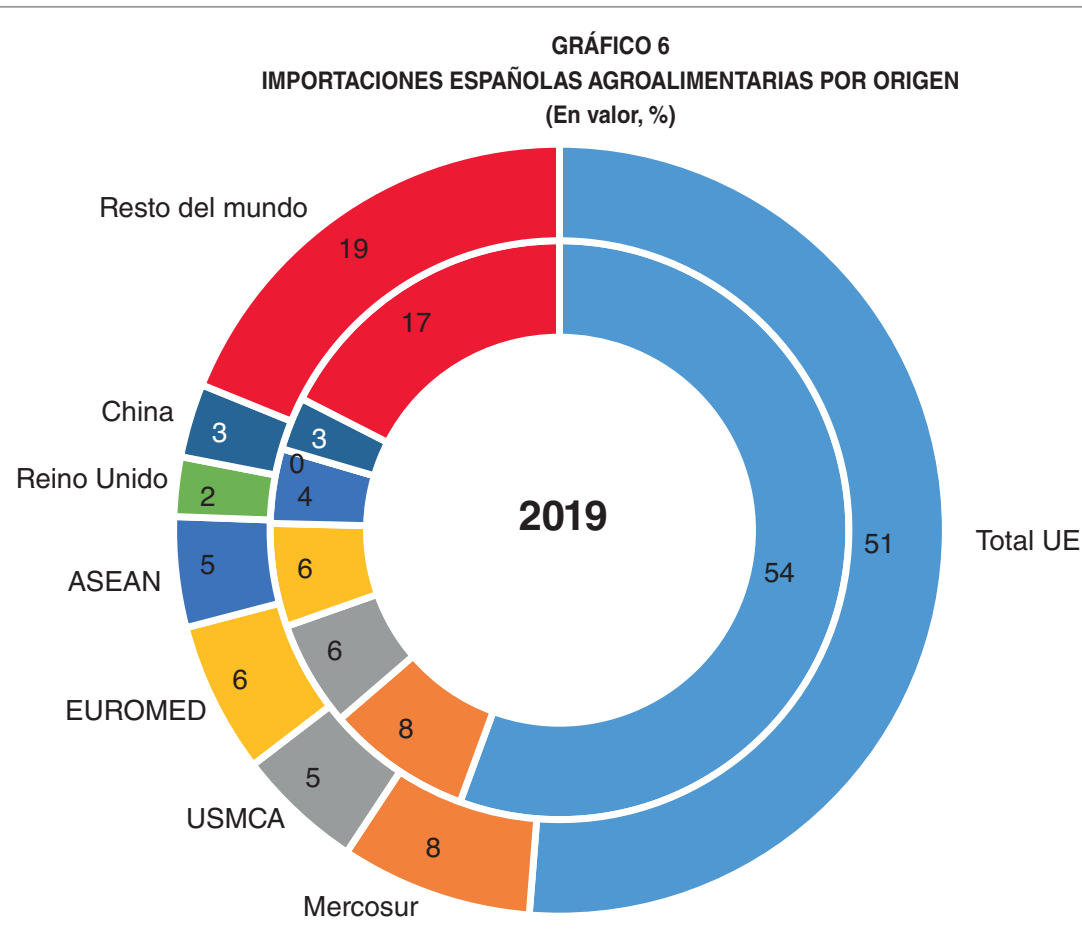

2020*

* Datos provisionales.

Fuente: elaboración propia con datos del Departamento de Aduanas e Impuestos Especiales. 


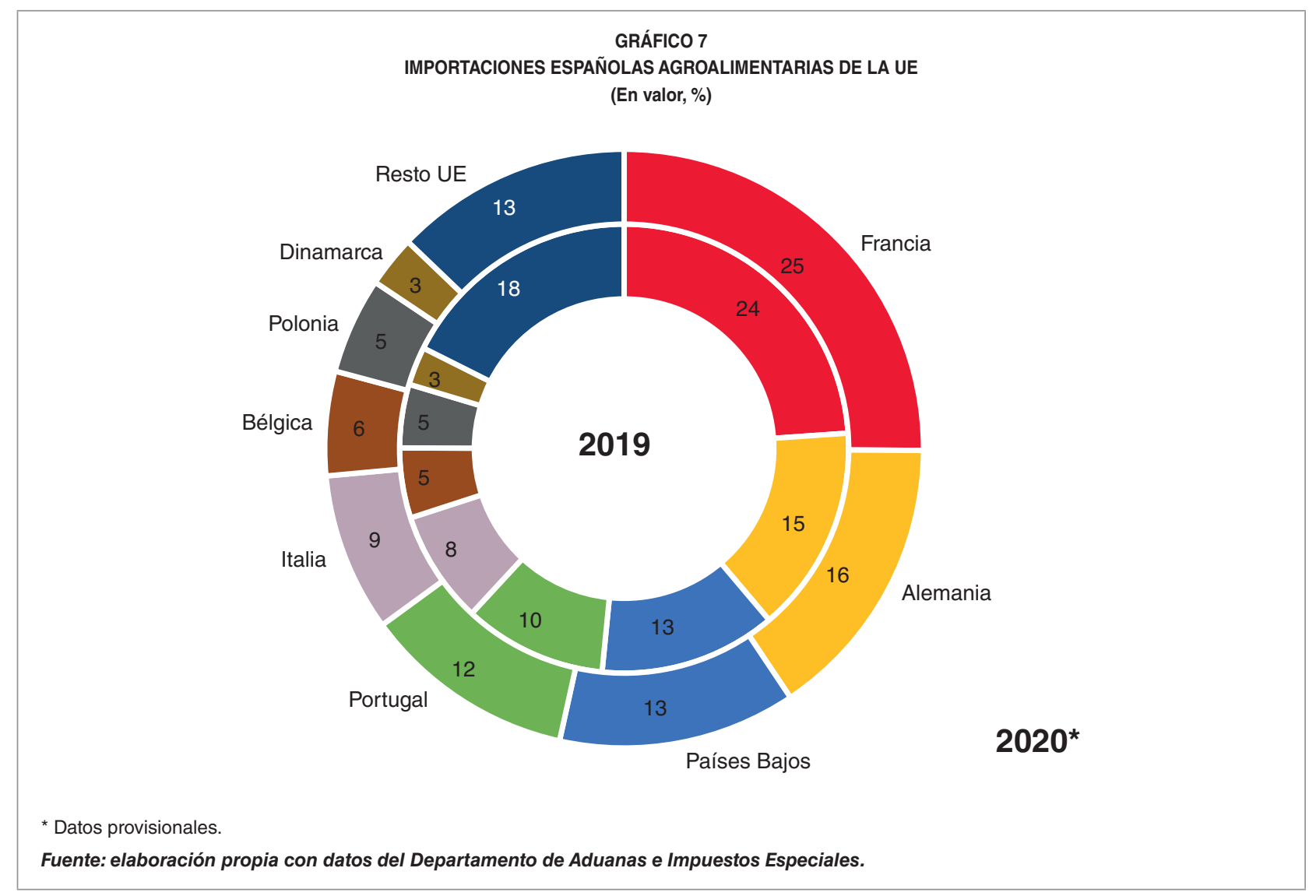

Reino Unido (2,5\%), Perú (1,9\%), Ecuador $(1,4 \%)$ y Chile $(1 \%)$.

El siguiente grupo de países, por orden de importancia, es el Mercado Común del Sur (Mercosur). Al igual que en 2019, Mercosur mantiene la segunda posición entre los principales proveedores. En términos porcentuales sobre el total de 2020, Mercosur representa el $19,2 \%$ en volumen (18,3\% en 2019 ) y el $8 \%$ en valor $(7,9 \%$ en 2019$)$. Las variaciones porcentuales respecto al año anterior indican un descenso en valor y en volumen $(-3,1 \%$ y $-6,2 \%$, respectivamente). Brasil y Argentina continúan siendo los principales proveedores tanto en volumen (5,8 millones y 1,9 millones de toneladas, respectivamente) como en valor (1.747 millones de euros Brasil y 1.004 millones Argentina).

El tercer grupo de países proveedores por valor de las importaciones son los países euromediterráneos (2,8\% del volumen y 6,3\% del valor), que han experimentado un sensible aumento de las exportaciones a España con respecto a 2019 , del $6,3 \%$ en volumen y del $7,4 \%$ en valor.

Por volumen importado, el tercer lugar lo ocupa USMCA, con el $5,1 \%$ del volumen y el $5,3 \%$ del valor total. Con respecto a 2019, las importaciones han disminuido fuertemente en volumen $(-33 \%)$ y también en valor $(-12,4 \%)$. Igual que en el caso de las exportaciones, alrededor de las tres cuartas partes ( $77 \%$ en valor) vienen de Estados Unidos.

También tienen relevancia las importaciones de la Asociación de Naciones del Sudeste Asiático (ASEAN), con un $5,1 \%$ del volumen y un $4,6 \%$ del valor total. Las importaciones de ASEAN han bajado un 3,3\% en volumen y han subido un $8,4 \%$ en valor. 


\section{Subdirección General de Comercio Internacional de Mercancías}

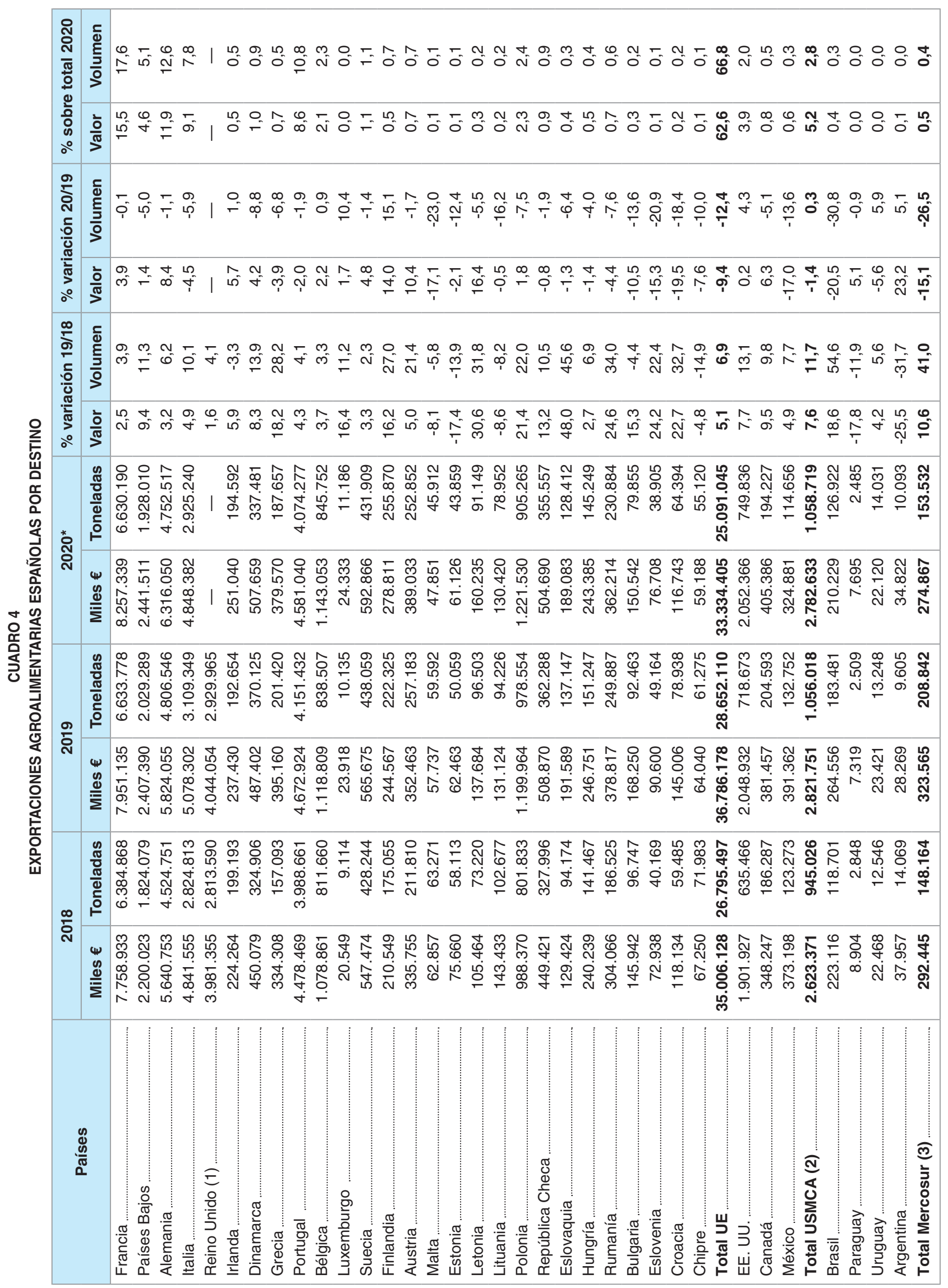




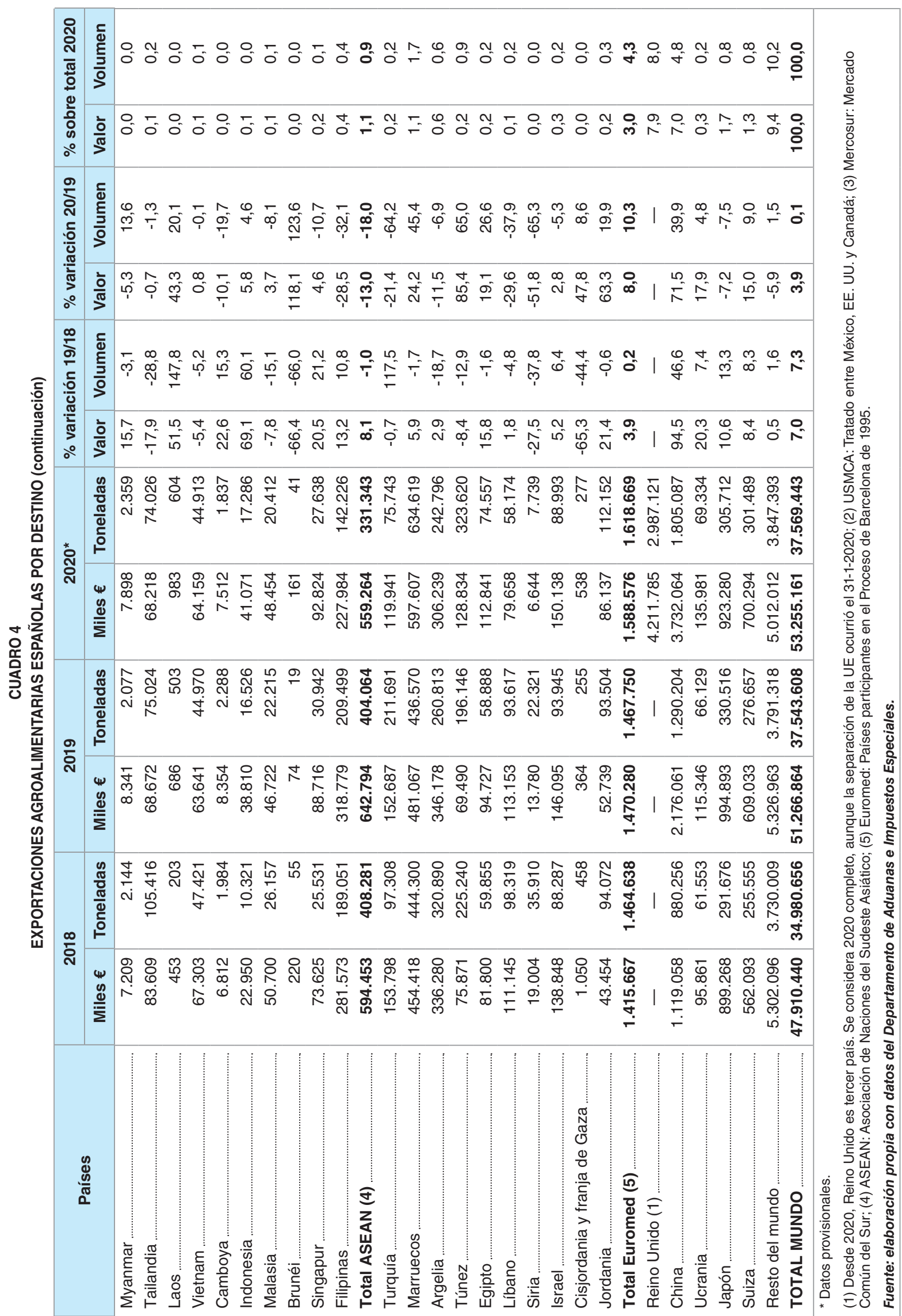




\section{Subdirección General de Comercio Internacional de Mercancías}

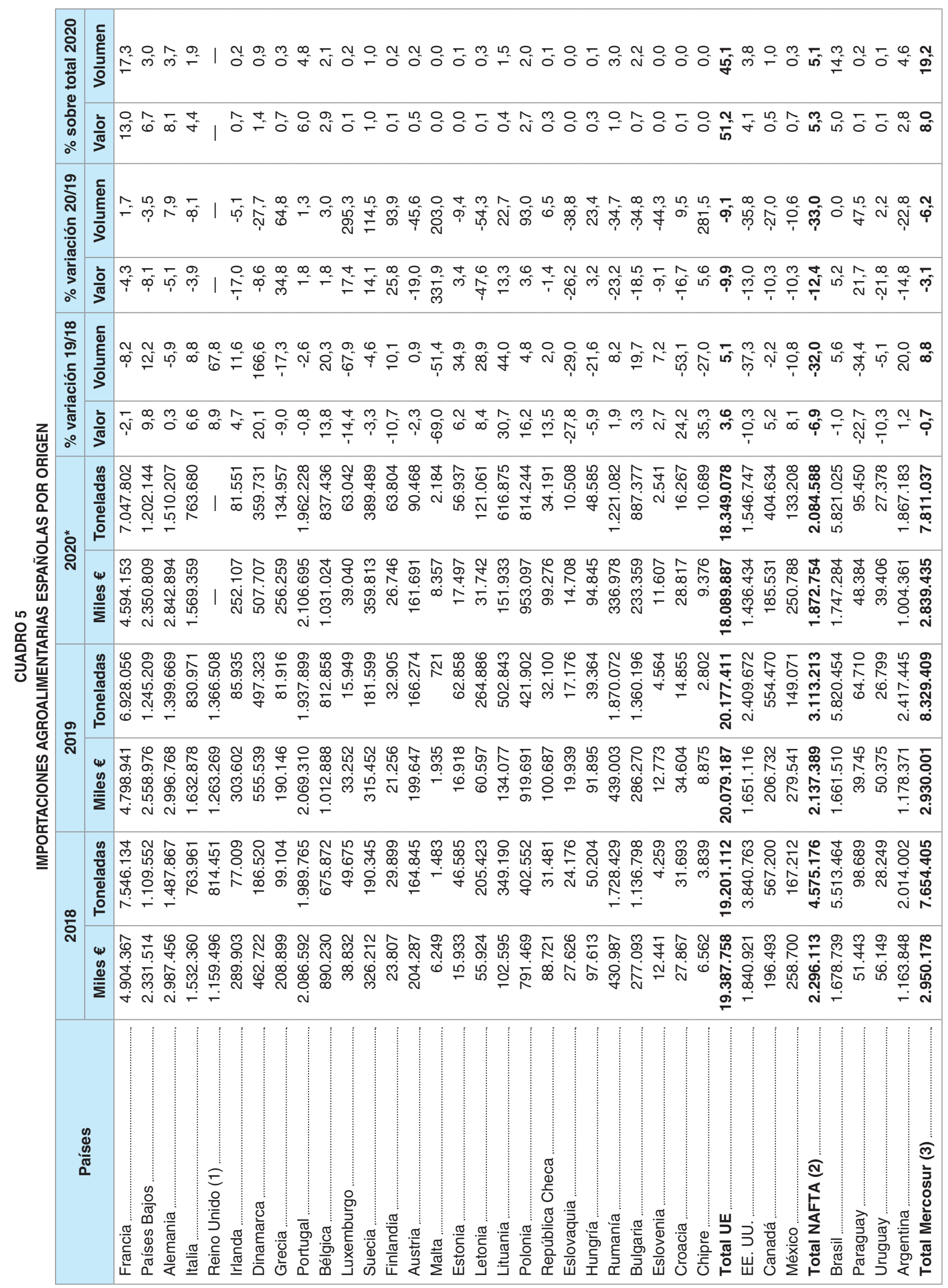




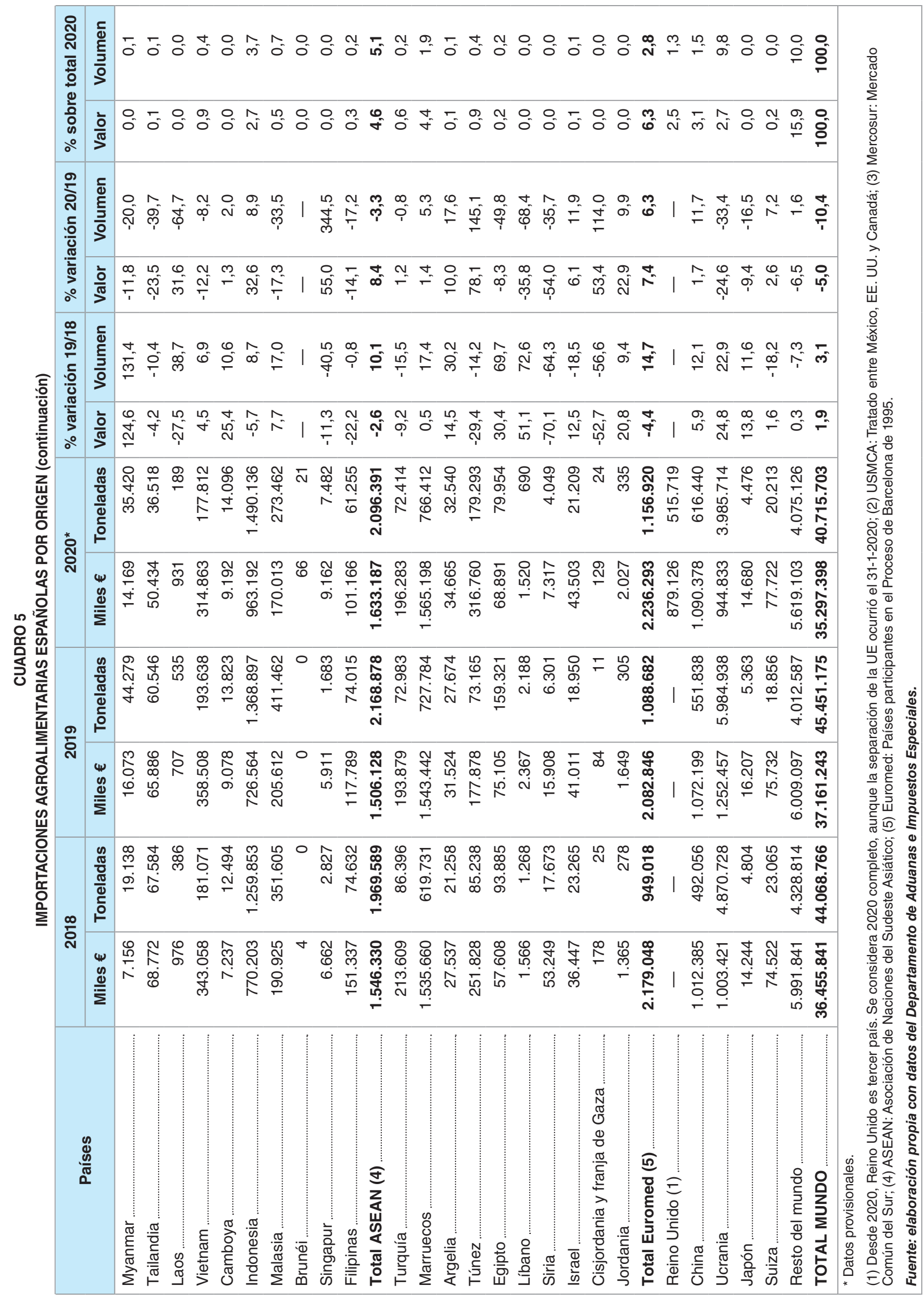




\section{Análisis sectorial del comercio exterior agroalimentario}

El análisis sectorial se presenta resumido en este artículo. (La balanza comercial con el análisis sectorial completo se encuentra en https://comercio.gob.es/ImportacionExportacion/Informes_Estadisticas/Paginas/Historico-Balanza.aspx).

El Cuadro 6 permite tener una visión de conjunto del comercio exterior por sectores, que se desarrolla en la versión completa de la balanza agroalimentaria.

En 2020 han tenido lugar algunos acontecimientos importantes con influencia en el comercio internacional de productos agroalimentarios y en su distribución. La salida de Reino Unido de la Unión Europea (Brexit) el 31 de enero de 2020 significa la consideración como tercero de este país, que queda fuera del mercado único de la UE, con consecuencias en el movimiento de mercancías por los controles aduaneros y otros controles como los sanitarios y de normas técnicas. Por otra parte, la irrupción a principios de 2020 de la pandemia por COVID-19 ha tenido influencia en el comercio, tanto por restricciones a la movilidad, sobre todo al principio, como por restricciones internas nacionales, que han provocado cambios en las pautas de consumo. Aunque no se puede conocer con exactitud la influencia que han tenido estos dos acontecimientos, es probable que se deba más a la pandemia, ya que en 2020 ha habido un periodo transitorio del Brexit (que finalizó el 31 de diciembre) durante el cual Reino Unido ha aplicado el acervo jurídico de la UE, lo que significa que, en relación al comercio, ha sido como si continuara en el mercado único. Como se ha comentado anteriormente, la distribución del comercio exterior entre la UE y terceros países ha cambiado en 2020 como consecuencia del Brexit.

Con todo, el comercio exterior de productos agroalimentarios se ha visto menos afectado que otros productos. Mientras que el valor de las exportaciones de todas las mercancías se ha retraído un $10,2 \%$ con respecto a 2019 , el de las exportaciones de productos agroalimentarios ha subido un 3,9\%. Las importaciones de agroalimentarios han bajado un $5 \%$, pero en menor medida que las de las importaciones de todos los bienes (-14,8\%). Como consecuencia, la participación de los productos agroalimentarios en el comercio exterior de bienes ha aumentado del $17,6 \%$ al $20,4 \%$ en las exportaciones y del $11,5 \%$ al $12,9 \%$ en las importaciones. En volumen, la exportación de productos agroalimentarios apenas ha variado $(0,1 \%)$ y la importación ha descendido un 10,4\%.

El año 2020 también ha sido el primero completo en que Estados Unidos ha aplicado medidas de represalia contra la UE, en forma de aumento de aranceles por un $25 \%$ adicional a una serie de productos, como consecuencia del conflicto en la Organización Mundial del Comercio por las subvenciones de la UE al consorcio Airbus. Estas medidas comenzaron a aplicarse el 18 de octubre de 2019 y, por lo que se refiere a España, en su mayoría se han aplicado a productos agroalimentarios. La importación en EE. UU. de los productos españoles afectados entre octubre de 2019 y septiembre de 2020 ha sido del $54,1 \%$, en relación con el mismo periodo del año anterior. De los productos de mayor relevancia, la reducción de las importaciones en EE. UU. ha sido, en el periodo indicado, del $72,4 \%$ en aceite de oliva, del $64,8 \%$ en vino, del $3,2 \%$ en aceitunas (aunque son de tipo distinto a las afectadas por los derechos compensatorios y antidumping impuestos en 2018 a las aceitunas negras españolas, ha empeorado $D$ 


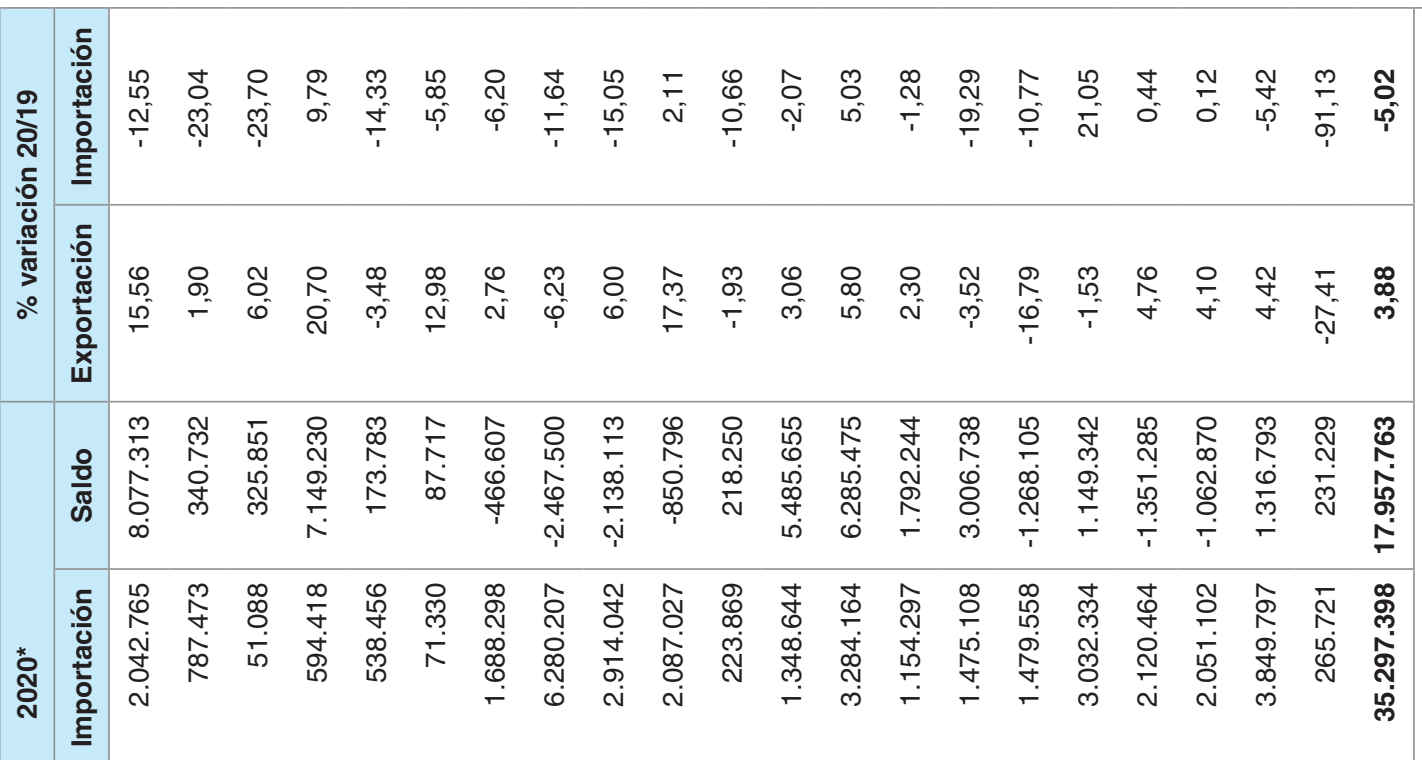

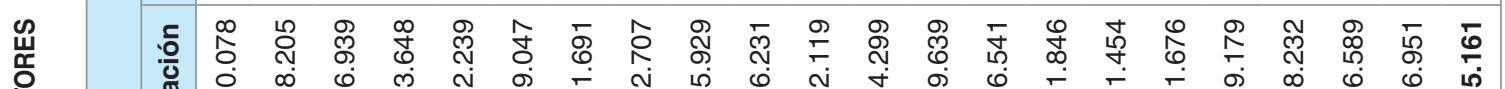

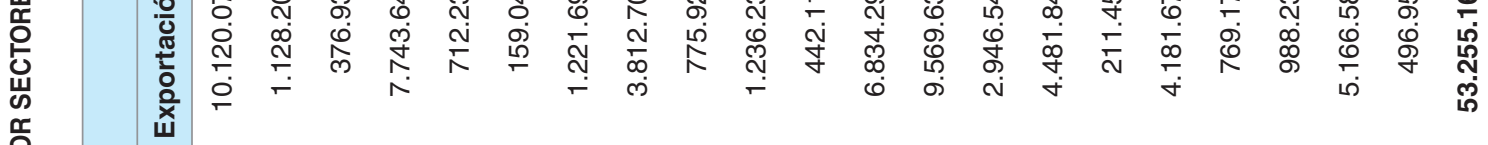

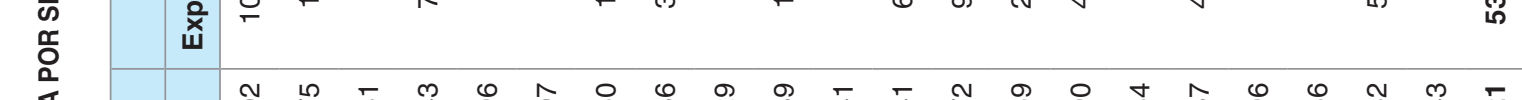

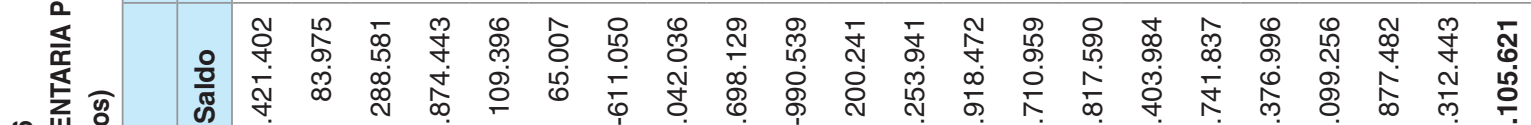
竞离

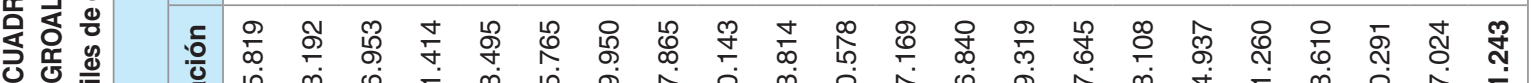

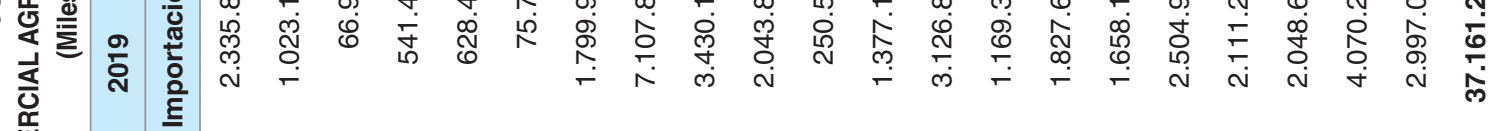

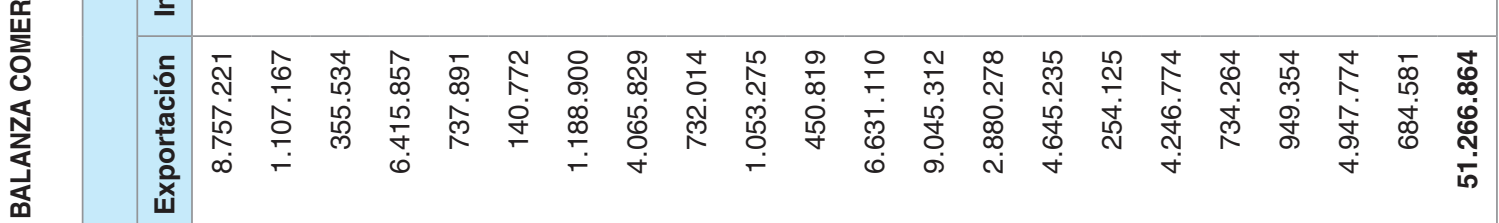

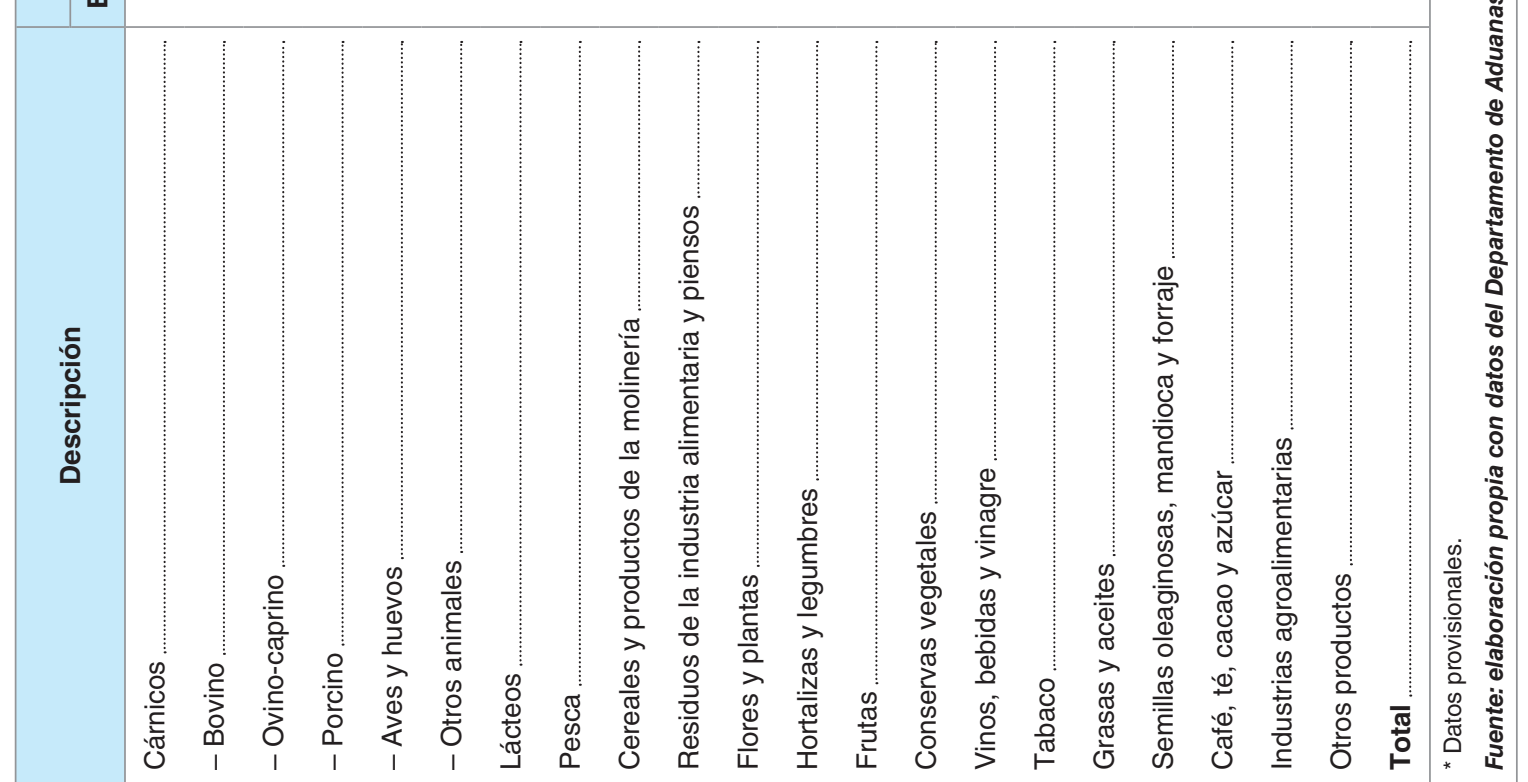


la situación de las exportaciones de aceitunas) y del $61,8 \%$ en quesos. Otros productos sancionados como la carne de porcino o las frutas han pasado de una importación reducida a una residual (entre las frutas, las más afectadas han sido los cítricos). Algún producto como las conservas de peras o melocotones no ha disminuido.

El año 2020 ha sido el primero completo en que se aplica el Acuerdo de Libre Comercio entre la UE y Singapur. Este acuerdo supone la eliminación de derechos arancelarios en Singapur para la práctica totalidad del comercio en un plazo máximo de cinco años y la eliminación de numerosas barreras no arancelarias.

En enero de 2020, Japón autorizó la exportación de carne española de bovino, de ovino y de caprino, mediante la aprobación de los requisitos sanitarios y certificados veterinarios correspondientes.

En febrero de 2020, tras la aprobación por Arabia Saudí de los certificados veterinarios correspondientes, se puede exportar a este país animales vivos bovinos, ovinos y caprinos.

El 26 de junio de 2020 entró en vigor la ley federal sobre la elaboración de vinos y la viticultura de la Federación de Rusia. Esta ley causa diversos problemas a los vinos españoles y comunitarios, entre los que destaca a efectos del comercio la prohibición del uso de vinos importados para elaborar vino en Rusia, lo que ha provocado una drástica reducción de las importaciones en este país del vino a granel español.

Las restricciones a la importación de productos agroalimentarios continúan en Argelia. Tras el aumento de aranceles en 2019, en julio de 2020, se ha impuesto la suspensión de importaciones de diversas frutas en determinadas épocas del año: frutos de hueso, de pepita, uvas, cítricos, granadas, membrillos, higos y almendras, estas últimas durante todo el año. Desde junio de 2020 no se ha producido ninguna importación en Argelia de carne de vacuno procedente de España, con excepción de la autorización a título excepcional de la importación de carne refrigerada por los importadores locales, por el Ramadán. Argelia no ha concedido licencias de importación desde el 31 de mayo de 2021 y ha suspendido las importaciones con el objeto de proteger su producción nacional. Argelia ha sido tradicionalmente de los principales países destinatarios de las exportaciones de carne roja desde España.

En julio de 2020, Kuwait levantó la prohibición que existía sobre la carne de vacuno española por la encefalopatía espongiforme bovina, por lo que se puede volver a exportar a dicho país.

El 1 de agosto de 2020 entró en vigor el Acuerdo de Libre Comercio entre la UE y Vietnam. Salvo algunos productos sensibles para los que se establecen contingentes arancelarios, casi todas las exportaciones de la UE a Vietnam serán liberalizadas en un plazo máximo de diez años y las importaciones de Vietnam, en siete años.

\section{Conclusión}

En 2020 se ha mantenido la tendencia, sostenida durante los últimos diecinueve años e intensificada desde la crisis económica, de saldos superavitarios de la balanza comercial agroalimentaria. El año 2020 también ha sido el del Brexit, acontecimiento sin precedentes por ser la primera vez que un país abandona la UE.

Esta evolución se ha producido en un contexto internacional caracterizado por tensiones en materia de política comercial y por negociaciones y puesta en marcha de nuevos acuerdos comerciales que, en algunos casos, han tenido efectos directos en los flujos de comercio exterior de productos agroalimentarios. 